CZU:821.135.1.09+398.2/.3

https://doi.org/10.52505/llf.2021.1.07

\title{
ÎN ETNOGENEZA MITICĂ A LUI BOGDAN PETRICEICU-HASDEU
}

\author{
Tatiana BUTNARU \\ Institutul de Filologie Română ,,Bogdan Petriceicu-Hasdeu” \\ ORCID: https://orcid.org/0000-0001-5771-9081
}

\begin{abstract}
Rezumat: Interesul lui B. P.-Hasdeu pentru mitologia autohtonă și-a găsit expresie într-o serie de investigații folcloristice în cadrul cărora au fost supuse discuției mai multe aserțiuni, opinii și probleme de cercetare din spiritualitatea geto-dacică. Mitologia autohtonă, în expresia ei modernă, se sprijină pe valorificarea tradițiilor populare, dezvăluie modalități de transfigurare artistică a realității prin prisma viziunilor și reprezentărilor ce caracterizează personalitatea creatoare a poporului român. Arhetipul Dochiei, la care exegetul revine de mai multe ori, constituie un model ipotetic, un simbolul emblematic al unui spațiu sacru de valori, circumscris în aspectele sale fundamentale. Dochia, personificarea străvechii Dacii, simbolizează, în accepția lui Hasdeu, constituirea istorică a românilor, care, în același timp, se încadrează și în resorturile unui cadru natural văzut în dimensiunile descriptive ale imaginației dacice în strânsă legătură cu miturile statorniciei.

Cuvinte-cheie: tradiție folclorică românească, surse de inspirație mitico-folclorice, inițiere estetică, arhetipul Dochiei, cultul lui Zamolxis, ontologie existențială, etnogeneză mitică.
\end{abstract}

\begin{abstract}
Hasdeu's interest for autochthon mythology found its embodiment in a series of investigations folklore, where discussion were proposed more assertions, opinions, research issues of spirituality Dacian. The autochthon mythology in its modern expression is based on the traditions, revealing ways of artistic transfiguration of reality in terms of visions and representations that characterizes the creative personality of the Romanian people. The archetype of Dochia that returns repeatedly is a hypothetical model, is an emblematic symbol of a sacred space circumscribed aspects of its fundamental values. Dochia is the personification of the ancient Gauls, it symbolizes in the acceptation of B. P. Hașdeu historical setting of the Romanians, but also a fall in natural springs descriptive saw the size of the imagination Dacian, closely related to the same myth of steadiness.

Key-words: Romanian folk tradition, mythical and folkloric inspiration, aesthetic initiation, archetype of Dochia, the cult of Zamolxis, existential ontology, the mythical ethnogenisis.
\end{abstract}

Cultul zeiţei-mume Dochia, cu multiplele ei semnificații individualizatoare, este una din preocupările fundamentale de cercetare în studiile lui B. P.-Hasdeu. Imboldul survine din dorința de reconstituire a vestigiilor trecutului, pentru a scoate la lumină nivelurile de gândire mitică ale stratului autohton 
și a dezvălui cele mai adânci zone ale spiritului popular. În acest scop, autorul propune o modalitate proprie de promovare a ființei naționale cu orientarea către genealogia primară.

Împietrirea Dochiei pe o stâncă din munții Ceahlău, la care se referă B. P.-Hasdeu într-o lucrare din tinerețe, este de origine mitico-legendară, dar, în același timp, ne duce cu gândul spre intuiția unor tărâmuri originare, este redată personificarea unui cadru natural văzut în dimensiunile descriptive ale imaginației dacice. „Pe una din terasele Ceahlăului, scrie B. P.-Hasdeu, se ridică o statuie neghioabă, neproporțională de cinci arșini, cunoscută în popor sub denumirea de Zeița Dochia. Ea reprezintă vag un chip de femeie căreia îi curge din față un izvor de apă. De jur împrejurul statuii sunt împrăștiate pietre mari, care au căpătat în imaginația poporului forma unor oițe” (Hasdeu, 2011, p. 104).

Străvechea legendă a naturii, cu oscilațiile ei caracteristice pentru echinocțiul de primăvară, transpare din învolburările spirituale ale timpului mitic; cercetătorul încearcă să reactualizeze ficțiunea mitică, sprijinindu-se pe descoperirile predecesorilor săi, pentru a reconstitui itinerarul emblematic al Dochiei în dimensiunile sale ontologice, cognitive, existențiale. „Dochia (Eudochia), subliniază în altă parte B. P.-Hasdeu, era fiica unui rege puternic, nespus de frumoasă, ea fiind urmărită, după cucerirea Daciei, de către Traian, se ascundea de el aici, păscând o turmă...” (ibidem, p. 99). În cele din urmă, după cum subliniază în continuare exegetul, "fiind găsită în acest adăpost, ea a fost transformată de către Zeu, la rugămintea ei, în statuie ca să nu-și piardă cinstea" (ibidem).

$\mathrm{O}$,replică mitică” referitoare la circulația acestui material legendar se regăsește și la R. Vulcănescu, unde „Dochia a fost prefăcută într-o bătrână ciobăniță, cu câteva oi lângă ea" (Vulcănescu, 1987, p. 269). Spre deosebire de alți cercetători și exegeți în domeniu, R. Vulcănescu a relevat în investigațiile sale științifice și aria de răspândire a acestui subiect mitico-legendar omniprezent ,în sud-estul Europei cu legende similare la bulgari, sărbi, albanezi și greci, însă fără corespondențe toponimice în geografia mitică a țărilor popoarelor menționate" (ibidem, p. 332).

În procesul de dezvăluire a arhetipurilor străvechi, inclusiv cel al Dochiei, Hasdeu se orienta într-o anumită măsură spre cunoscuta legendă a lui Gh. Asachi Traian și Dochia, publicată în 1840, în dorința de a promova reconstituirea unui spațiu sacru de valori în aspectele sale fundamentale. Luând în discuție lucrarea respectivă, savantul făcea abstracție de ficțiunea mitică: „eu nu împărtășesc legenda populară, pentru că legenda nu este un eveniment real" 
(Hasdeu, 2011, p. 99), dar și-a sprijinit aserțiunile în baza unor documente vechi și a muncii de cercetare pe teren, fiindcă, așa cum precizează Hasdeu în continuare, nu numai Gh. Asachi, dar și „cuvintele lui Cantemir m-au făcut să introduc pe Dochia în mitologia românească” (ibidem, p. 99-100).

Pe deplin convins că ,înțelepciunea care te duce pe drumul desăvârșit se află în folclorul fiecărui popor” (Ștefan, 2006, p. 8), Hasdeu are inspirația să creeze cadrul mitic al unui spațiu originar, unde și-a găsit expresie „putința perceperii de învățături menite să ridice conștiința la asemenea nivel, încât să poată să vină la timpul potrivit în contact cu adevărul" (ibidem). Imboldul spiritual al lui B. P.-Hasdeu se manifestă din dorința de reconstituire a adevărului științific; autorul pornește de la niște izvoare de cunoaștere esoterică ca să scoată în lumină nivelurile de gândire mitică ale stratului autohton, orientând cititorul spre cele mai adânci zone ale spiritualității autohtone, care pare să fi coborât de undeva din conștiința universală. Aceste interpretări, aserțiuni aveau menirea să elucideze „punctele de plecare mitologice ale orientării scriitorilor naționali, iar un străin care nu le-ar cunoaște ar pierde mult din semnificația poeziei noastre moderne" (Călinescu, 1982, p. 62). Se înțelege, cercetătorul avea în vedere simbolul emblematic al unui spațiu de valori, „apropiat de viziunea prin suflet al unui fenomen primar” (Bălăeț, 1979, p. 35). Pentru a determina autenticitatea trecutului geto-dacic din muntele Ceahlău, B. P.-Hasdeu încearcă să releve legătura dintre statuie și mitul Dochiei, privită fiind drept o realitate istorică de cult pentru epoca respectivă. Iniţiativa de a polemiza cu D. Cantemir în problema respectivă se manifestă prin dezacordul cu opinia acestuia, potrivit căreia „statuia ar trebui să fie o reprezentare a unei zeițe păgâne" (Hasdeu, 2011, p. 100). Cercetătorul invită cititorul la discuție în baza mai multor aserțiuni, păreri și opinii, ca, în cele din urmă, să ajungă și la alte constatări generalizatoare referitoare la semnificația originilor. „Este greu, firește, de spus dacă natura a arătat în acest monument jocurile sale, precizează Hasdeu, ori dacă o mână dibace de artist a făcut-o așa" (ibidem, p. 99).

Disponibilitatea imaginativă a lui B. P.-Hasdeu față de etnogeneza mitică despre Dochia se manifestă prin „mai multe nivele”: pe de o parte, se are în vedere „mitul arhaic păstoresc-universal”, făcându-se referință la cunoscuta legendă a naturii, când Dochia, lăsând cojoacele, îngheață și se pietrifică într-o stâncă; iar pe de altă parte, este întrevăzut „un mit istoric”, care se prezintă drept „o soluție de transcendere a impasului, ca o implinire dată de Zamolxis rugăminții fetei de împărat, care își va apăra în această ipostază integritatea ființei” (Babu-Buznea, 1979, p. 128). 
Având cunoștințe profunde în domeniul civilizațiilor străvechi, Hasdeu aduce argumentele sale de rigoare pentru a prezenta niște lecții ale istoriei, dar și de a demonstra în mod concret originea autohtonă a stratificării statuii de pe Ceahlău, care în mod veritabil „reprezintă singurul monument dac” [...] „printre mulțimea de idoli slavi” (Hasdeu, 2011, p.101), iar vechea legendă populară despre Dochia capătă o nouă plenitudine, devine un simbol matern cu multiple semnificații, este o „Magna Mater”, cum este numită în mai multe studii etnologice, cu orientare pentru neamul de păstori din care face parte, ea transpare drept o „mumă” a poporului român, dar și a naturii în germinația ei totalizatoare, este „mama soarelui, mama ploii, mama florilor, mama lui Dumnezeu" (Hanganu, 2008, p. 30). Dochia mai este întrevăzută și cu semnificația de obârșie sau origine, fiindcă în accepția populară ,,nu e nimic pe lume care să nu aibă o mumă, o maică” (Herseni, 1982, p. 226), adică un început. Argumentele expuse au o multiplă perspectivă de abordare a arhetipurilor din mitologia dacică, cu alte cuvinte, Dochia-Mumă este orientată spre semnificația originilor. Este vorba de cultul strămoșilor perceput în dependență de argumentele referitoare ,la ciclul anual al zeităților vegetației cu aspectele lor telurice și htoniene" (Mușu, 1982, p. 73). Or, cercetătorii au pus nu o singură dată „problema existenței la geto-daci a unei zeițe feminine a pământului, soție a lui Zamolxis, zeitatea pământului în creșterea și descreșterea sevelor acestuia, înveșmântarea de plante și roade, dezbrăcată de acestea" (ibidem, p. 76).

Aserțiunile expuse sunt susținute și de I. Ghinoiu, care întrevede în arhetipul Dochiei, alături de metamorfozele ei calendaristice, ,,amintirea Marii Zeițe (Terra Mater) și este identificată cu Diana și Iuno din panteonul roman, cu Hera și Artemis din panteonul grecesc” (Ghinoiu, 1997, p. 64). „In analogie cu zeitățile feminine la popoarele trace, Dochia este apreciată drept o divinitate agrară și maternă la vârsta senectuții” (ibidem). La fel ca și Zamolxis, Zeița-Mumă Dochia este predestinată să-și trăiască plenar evaziunea în mitul solar al universului. Amplasată la hotarul dintre desișurile greu de străbătut în ambianța naturală a Daciei și imperiul zeilor, Dochia transpare în ipostaza de „Marea Mamă a Zeilor”, „Magna Mater Deorum”, ,o mama a naturii, natură a tuturor lucrurilor, stăpâna munților și a stihiilor”, „ocrotitoarea păstorilor” (ibidem, p. 107).

$\mathrm{Cu}$ referire la această stare de lucruri, Mircea Eliade, la rândul său, întrevede în toate culturile arhaice - fie ele agricole, fie maritime... - principiul feminin sub forma unei Mame, a unei Mari Zeițe creatoare și păstrătoare a Cosmosului. Unitatea geniului omenesc a fost descoperită după ce s-a desco- 
perit unitatea Cosmosului: căci Magna Mater e o mamă a Totului, a Zeilor, ca și a oamenilor. Magna Mater a avut rolul formulei care unifică. Unifică nu numai Cosmosul, ci chiar și neamul omenesc (Eliade, 2003, p. 20).

În baza unui bogat material factologic, din intenția de , a hrăni sufletul cu spiritualitate", Hasdeu încearcă să depisteze niște nuanțe suplimentare ale zeităţilor feminine din miturile autohtone, făcând o analogie dintre personajul dacic și întruchipările Zeiței-Mame „din lumea pelasgică” (Hasdeu, 2011, p. 106), a căror supremație se manifestă prin niște calități magice deosebite, ele asigură fertilizarea naturii și a universului, după cum putem surprinde din relatările lui Apuleius, pe baza cărora Hasdeu se documentează în elaborarea investigațiilor sale științifice. În această ordine de idei, evidențiem un fragment preluat și interpretat de Hasdeu: „Eu sunt mama natură a tuturor lucrurilor, stăpâna stihiilor, (devoratoarea) secolelor, eu sunt suverana împăraților, regina umbrelor, tăcerea sumbră a iadului. Divinității mele unice, deși multilaterale, i se închină toată lumea, sub diferite nume. Unii mă numesc Mama Zeilor, alții Artemis" (ibidem, p. 107). În contextul mărturiilor antice preluate de Hasdeu, este explicabilă și poziția lui I. Oprișan, care, în comentariile sale la volumul de folcloristică a lui B. P.-Hasdeu, încerca să ne convingă despre ,importanța multiplă a Zeiței-Mume”, materializată prin ,venerația și încarnările alegorice” ale acestui arhetip mitic, „importanța ei religioasă și cosmică”, precum și prezența unor ,ample incursiuni din mitologia, limba și istoria tracilor" (Oprișan, 2011, p. 466).

Este interesantă și discutabilă în același timp și aserțiunea lui N. Densușianu, care, de asemenea, se referea la "figura Dochiei sau a Mamei Mari din Dacia" (Densușianu, 1982, p. 30), atribuindu-i o semnificație mitică aparte: pe de o parte, exegetul întrevede în arhetipul Dochiei oscilațiile calendaristice ale timpului de primăvară, pe de altă parte, este celebrată o zeitate maternă supremă din tradiția populară cu numele Dochiana. „Dochiana cea frumoasă din colindele agrare”, după cum ne sugerează în incursiunile sale științifice N. Densușianu, ,,se înfățișează ca o virgină foarte frumoasă ce nu îmbătrânește și se manifestă în ipostaza de zeiță a fertilității pământului" (Densușianu, 1982, p. 30). „Nu există nici un contrast între aceste două tradițiuni poporale, precizează în continuare N. Densușianu, cu privire la baba Dochia cea împietrită și la Dochiana cea frumoasă. În colindele române se celebrează tinerețea, frumusețea extraordinară și castitatea Mamei-Mari, iar legendele se referă la a doua parte a vieții sale, în particular la apoteoza sa" (ibidem, p. 183-194), cu alte cuvinte, este celebrată frumusețea și jubilația sărbătorească a naturii în dimensiunile sale ontologice fundamentale. 
Prin urmare, arhetipul Dochiei include inițierea într-un sistem mitologic de referință și are orientare către neamul de păstori din care face parte, este vorba de un „spațiu etern care nu dispare și pe fiecare îl descoperă prin confundarea în el însuşi” (Bomher, 1994, p. 1). Având o disponibilitate aparte faţă de mitologia autohtonă, Hasdeu aduce niște constatări îndrăznețe, stabilește analogii și legături, găsește soluții de abordare a materialului de investigație științifică. Portretul mitic al Dochiei este prezentat într-un spațiu străvechi, marcat de ideea dacică a nemuririi, reconstituit în baza diferitor surse documentare referitoare la mitologia națională. Respectiv, cercetătorul îndeamnă spre inima istoriei, unde în prim plan se află ,moșii patres, moșii patria, așa cum ne sugerează, la rândul său, și O. Babu-Buznea, cu orânduielile lor bune și drepte, cu limba lor spornică și bogată, cu moștenirea lor inteligentă și socială întemeiată pe o mare epocă eroică și pe o dezvoltare normală și sănătoasă” (Babu-Buznea, 1979, p. 159). B. P.-Hasdeu are inspirația să reconstituie itinerarul emblematic al Dochiei pe temelia unor resorturi mitico-legendare, în dependență de materialele puse la dispoziție, în baza diferitor studii de arhivă, dar și în legătură directă cu resorturile imaginației sale creatoare, care s-ar sprijini pe reconstituiri și pe descoperirea unor surse sigure de informare, în vederea aprofundării etnologiei etnice a românilor constituită de secole. Zeița-Mumă Dochia exprimă un tip de divinitate care figurează deseori alături de cultul lui Zamolxis și se află în strânsă legătură cu arhetipurile solare suprapuse polarității lor existențiale, precum și cu diferite personaje feminine din folclorul nostru ritualic, care, de asemenea, derivă din codul genetic al Zeiței-Mume. Într-un studiu despre credințele populare și ,,locuința zânelor în Țara Românească” (Hasdeu, 2011, p. 431), Hasdeu ne orientează, dintr-o perspectivă participativă, la aprofundarea unui cosmos divin, unde ,plantele-zâne” manifestă o disponibilitate aparte față de „Ilie Cociașul”, care ar putea fi tălmăcit cu sensul de „Zeul de Soare”, ,conducător la carul soarelui peste bolta cerului" (ibidem). Cele nouă zâne, invocate cu deosebită căldură de Hasdeu, au niște funcții mitice bine individualizate și pot fi asociate cu niște zeități feminine din „,raiul Dochiei”, având legătură cu pământul, vegetația, apele, văzduhul. Mai bine-zis, are loc integrarea într-un spațiu mitic condensat până la saturație de niște stări sufletești de excepție, ceea ce amplifică ideea înfloririi, a germinației totalizatoare, așa cum vedem din miturile Dochiei.

Îndrăgostit de spiritualitatea poporului său, concretizată în mituri, arhetipuri și tradiții folclorice, savantul B. P.-Hasdeu le-a dezvăluit într-o nouă lumină, pentru a le pune în circulație și a le promova în vederea perpetuării lor prin 
timpuri și generații. În ipostaza de deschizător de drumuri în studierea mitologiei autohtone, Hasdeu are meritul de a face prima tentativă de investigație a sufletului popular, pregătind terenul în evocarea unor momente de vârf din istoria românilor, fenomen preluat și în lucrările altor personalităţi marcante ale culturii noastre naționale. Problema rămâne deschisă, iar ceea ce a realizat B. P.-Hasdeu în elucidarea itinerarului spiritual al Zeiței-Mume Dochia este un imbold și pentru alte cercetări în domeniul mitologiei autohtone.

\section{Referințe bibliografice:}

1 BABU-BUZNEA, Ovidiu. Dacii în conștiința romanticilor noștri. București: Editura Minerva, 1979.

2 BĂLĂET, Dumitru. Eterna regăsire. Craiova: Editura Cartea Românească, 1979.

3 BOMHER, Noemi. Mit și mitologie eminesciană. Iași: Editura Virginia, 1994.

4 CĂLINESCU, George. Istoria literaturii române de la origini până în prezent. București: Editura Minerva, 1982.

5 DENSUȘEANU, Nicolae. Dacia preistorică. București: Editura Meridiane, 1982.

6 ELIADE, Mircea. Mitul reintegrării. București: Editura Humanitas, 2003.

7 GHNOIU, Ion. Datini și tradiții populare de peste an. București: Editura Fundației Culturale Române, 1997.

8 HANGANU, Lilia. Subiecte, motive, imagini comune în folclorul epic al românilor și bulgarilor. Chișinău: Editura Pontos, 2008.

9 HASDEU, Bogdan - Petriceicu. Adorația soarelui. În: B. P.-Hasdeu. Scrieri. Vol. 5. Chișinău: Ștința, 2011.

10 HASDEU, Bogdan - Petriceicu. Zeița Dochia și babele de piatră. În: B. P.-Hasdeu, Scrieri. Vol. 5. Chișinău: Știința, 2011.

11 HASDEU, Bogdan - Petriceicu. Zeița-Mumă. În: B. P.-Hasdeu. Scrieri, vol. 5. Chișinău: Întreprinderea Editorial-Poligrafică Știința, 2011.

12 HERSENI, Teodor. Forme străvechi de cultură poporană românească. Studii de paleontologie a cetelor de feciori din Țara Oltului. Cluj-Napoca: Editura Dacia, 1977.

13 MANGIUCĂ, Gheorghe. Botanica poporană română. Din însemnătatea Botanicii românești. Recenziune. În: B. P.-Hasdeu. Scrieri. Vol. 5. Chișinău: Știința, 2011.

14 MUȘU, Gheorghe. Din mitologia tracilor. București: Cartea Românească, 1982.

15 OPRIȘAN, Ion. Note și comentarii ale credințelor mitologice la români. În: B. P.-Hasdeu. Scrieri. Vol. 5. Chișinău: Știința, 2011.

16 ȘTEFAN, Alexandru. Pe urmele lui Zamolxe. Carpatia. Chișinău: Editura Muzeum, 2006.

17 VULCĂNESCU, Romulus. Mitologie română. București: Editura Academiei, 1987.

Notă. Articolul a fost realizat în cadrul proiectului de cercetare 20.80009.1606.03 Contexte socio-culturale autohtone și interconexiuni europene în creația populară și literatura cultă din Basarabia (sec. XIX până în prezent), Institutul de Filologie Română „Bogdan Petriceicu-Hasdeu” al MECC. 